\title{
Magnetic gold nanoparticle-mediated small interference RNA silencing Bag-1 gene for colon cancer therapy
}

\author{
WENBAI HUANG, ZHAN'AO LIU, GUANZHOU ZHOU, AILING TIAN and NIANFENG SUN \\ Department of General Surgery, Qilu Hospital of Shandong University, Jinan, Shandong 200012, P.R. China
}

Received September 8, 2015; Accepted October 19, 2015

DOI: $10.3892 /$ or.2015.4453

\begin{abstract}
Bcl-2-associated athanogene 1 (Bag-1) is a positive regulator of $\mathrm{Bcl}-2$ which is an anti-apoptotic gene. Bag-1 was very slightly expressed in normal tissues, but often highly expressed in many tumor tissues, particularly in colon cancer, which can promote metastasis, poor prognosis and anti-apoptotic function of colon cancer. We prepared and evaluated magnetic gold nanoparticle/Bag-1 siRNA recombinant plasmid complex, a gene therapy system, which can transfect cells efficiently, for both therapeutic effect and safety in vitro mainly by electrophoretic mobility shift assays, flow cytometric analyses, cell viability assays, western blot analyses and RT-PCR (real-time) assays. Magnetic gold nanoparticle/Bag-1 siRNA recombinant plasmid complex was successfully transfected into LoVo colon cancer cells and the exogenous gene was expressed in the cells. Flow cytometric results showed apoptosis rate was significantly increased. In MTT assays, magnetic gold nanoparticles revealed lower cytotoxicity than Lipofectamine 2000 transfection reagents $(\mathrm{P}<0.05)$. Both in western blot analyses and RT-PCR assays, magnetic gold nanoparticle/Bag-1 siRNA recombinant plasmid complex transfected cells demonstrated expression of Bag-1 mRNA $(\mathrm{P}<0.05)$ and protein $(\mathrm{P}<0.05)$ was decreased. In further study, $c$-myc and $\beta$-catenin which are main molecules of $\mathrm{Wnt} / \beta$-catenin pathway were decreased when Bag-1 were silenced in nanoparticle plasmid complex transfected LoVo cells. These results suggest that magnetic gold nanoparticle mediated siRNA silencing Bag-1 is an effective gene therapy method for colon cancer.
\end{abstract}

\section{Introduction}

According to the 2014 cancer statistics from the American Cancer Society, colon cancer is the third cause of human cancer

Correspondence to: Dr Nianfeng Sun, Department of General Surgery, Qilu Hospital of Shandong University, 107 West Wenhua Road, Jinan, Shandong 200012, P.R. China

E-mail: nianfengsun@126.com

Key words: colon cancer, LoVo cells, gene therapy, Bag-1 gene, small interfering RNA, magnetic gold nanoparticles incidence and mortality. A total of 96,830 new colon cancer cases and 50,310 deaths are projected to occur in the US in 2014 (1), and these numbers are still indicating an increasing trend each year. Treatment of colon cancer is primary surgery, supplemented by radiotherapy and chemotherapy, while surgery is difficult to completely remove tumor cells, remaining cells may cause tumor recurrence and metastasis. Besides, due to their severe side-effects and drug resistance, radiotherapy and chemotherapy are greatly limited in clinic. Currently, gene therapy is the focus of cancer treatment, and many research efforts have already been made. However, the effects of gene therapy are still unsatisfactory $(2,3)$. The mechanisms of tumorigenesis are complex, and specific target genes for therapy are difficult to identify. A common belief is that apoptosis is an important mechanism of tumorigenesis. Inducing tumor cell apoptosis effectively is the key of successful cancer treatment (4). Studies have proved that Bcl-2-associated athanogene 1 (Bag-1) one of most important anti-apoptotic genes, its mutation is an important molecular biological basis of colon cancer, as well as a key part in development and progression of colon cancer. Bag-1 protein is a multifunctional binding protein, which can enhance the anti-apoptotic ability of Bcl-2 family members (5). In our previous studies, we found that Bag-1 expression was significantly higher in colon cancer tissues than normal colon tissue, both in colon cancer cells cytoplasm and nucleus. In addition, Bag-1 expression level is proportional to the level of colon cancer malignancy, which indicates Bag-1 plays an important role in the occurrence and development of colon cancer (6). Studies have also shown that knockout Bag-1 gene can inhibit transcriptional activity of $\mathrm{NF}-\kappa \mathrm{B}$ in colon cancer cell lines (7).Therefore, Bag-1 gene as a target for cancer therapy, specifically blocking its expression, is expected to be an effective in colon cancer gene therapy.

Gene therapy is limited by the gene delivery system. It is generally known that virus gene vectors cannot be repeatedly applied in the body, and serious potential unknown effects exist. On the contrary, non-virus gene vectors are safer and have no known serious side effect, with low toxicity, low immune response and active surface modification characteristics. While, low target specificity and poor transfection efficiency are apparent defects of common non virus gene vectors that limits their applications on clinic. Nanoparticles are new nonviral vectors, which have received great attention in recent years. Nanoparticles are solid colloidal particles with diameter range from 10 to $500 \mathrm{~nm}$, which can enhance gene resistance 
ability to nuclease, prevent them from degradation, increase their stability in cells and realize controlled-release, extending their effective duration time in vivo $(8,9)$. Nanoparticles are non-toxic, non-immunogenic and biodegradable (10). In addition, nanoparticles have tissue penetration ability, which can easily absorbed by cells (11). The above make nanoparticles unique and superior gene therapy vectors $(12,13)$. The present study applied magnetic gold nanoparticles as gene vectors for loading the recombinant plasmid which was inserted by Bag-1 RNAi gene to transfect into colon cancer cells. In this way, we detected and analyzed the effects of silencing Bag-1 gene for colon cancer gene therapy.

\section{Materials and methods}

Optimal ratio of nanoparticles and Bag-1 RNAi recombinant plasmid. Seven aliquot magnetic gold nanoparticles were mixed with plasmid solution respectively, according to mass ratio of 1: 1,2:1,3: 1,4:1, 5: 1, 10:1, 15: 1, and incubated for $20 \mathrm{~min}$. Electrophoretic mobility shift assays analyzed the combine ratio of each group, then selecting the optimal ratio.

Preparation of nanoparticle/Bag-1 RNAi recombinant plasmid complex. We placed the required magnetic gold nanoparticles to $1.5 \mathrm{ml} \mathrm{EP}$ tube, added quantitative serum-free F-12 medium for $5 \mathrm{~min}$; according to optimal combine ratio of magnetic gold nanoparticles and plasmid, corresponding amount of quantitative serum-free F-12 medium was used to dilute the plasmids, mixed them lightly in the EP tube, then incubated at room temperature for $20 \mathrm{~min}$. Magnetic gold nanoparticle/Bag-1 RNAi recombinant plasmid complex was prepared.

Cell culture and siRNA transfection. Human colon cancer cell lines (LoVo) were obtained from Cell Resource Center of Shanghai Institutes for Biological Sciences. All cells were routinely cultured in F12 medium supplemented with $10 \%$ fetal bovine serum (FBS) and $1 \%$ penicillin-streptomycin at $37^{\circ} \mathrm{C}$ in humidified atmosphere of $5 \% \mathrm{CO}_{2}$ in air. For transfection, cells were divided into 4 groups (Nano-Plasmid, Nano and Plasmid transfections, and control group) and transfected with the nanoparticle plasmid complex, magnetic gold nanoparticles, Bag-1 RNAi recombinant plasmid and serum-free F-12 medium, respectively, according to the manufacturer's instructions of magnetic gold nanoparticles (GodMag, Xi'an, China). Transfection was efficiency assessed by phase-contrast microscope and fluorescence microscopy at 24, 48 and $72 \mathrm{~h}$ after transfection. Cell apoptosis and transfection efficiency were assessed by flow cytometry (FCM) at highest transfection efficiency, time detected by phase-contrast microscope and fluorescence microscopy.

Cell viability assay. Cell viability was measured by MTT assay (MTT; Dojindo, Kumamoto, Japan). In brief, LoVo cells $\left(5 \times 10^{3} /\right.$ well $)$ were seeded into 96 -well plates and were transfected with magnetic gold nanoparticles, the nanopartilce plasmid complex, serum-free F-12 medium (as control group) and Lipofectamine 2000 transfection reagent, respectively. After transfection for 24,48 and $72 \mathrm{~h}$, MTT reagents were added and were incubated with the cells for

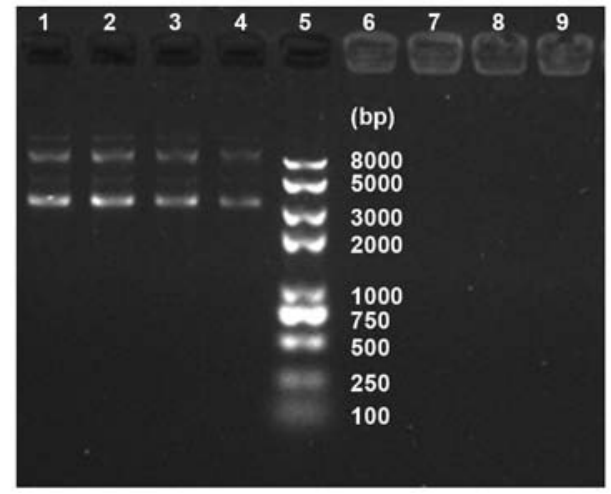

Figure 1. Optimal ratio of nanoparticles and Bag-1 RNAi recombinant plasmid: Lane 5, DNA maker; lane 1, naked plasmid, and the lanes from 2 to 4 and 6 to 9 , respectively, the mass ratio of $1: 1,2: 1,3: 1$ and $4: 1,5: 1,10$ : 1, 15: 1 .

$1 \mathrm{~h}$. Then, the absorbance was detected at $450 \mathrm{~nm}$ according to the manufacturer's instruction. Cell viability $=$ (the average OD value of experimental group/the average OD value of control group) $\mathrm{x} 100 \%$.The experiments were performed in triplicate (14).

Cell apoptosis assay. Apoptosis was assayed using the Annexin V-PE/7AAD apoptosis detection kit (Invitrogen, Carlsbad, CA, USA) according to the manufacturer's instructions. Briefly, the cells were harvested, washed twice with phosphate-buffered saline (PBS), centrifuged at 1,000 x $\mathrm{g}$ for $5 \mathrm{~min}$ and resuspended in $195 \mu \mathrm{l}$ Annexin V-PE binding buffer. Then, $5 \mu$ l Annexin V-PE was added gently at room temperature. After staining for $10 \mathrm{~min}$ in the dark, the cells were centrifuged at $1,000 \mathrm{x} \mathrm{g}$ for $5 \mathrm{~min}$, and then gently resuspended in $190 \mu \mathrm{l}$ of Annexin V-PE binding buffer and $10 \mu \mathrm{l}$ of 7AAD staining solution was added to the cells, gently mixed and kept on ice in the dark. The cells were analyzed by FCM (15).

$R T-P C R$. Total RNA was extracted from cultured cells using the TRIzol reagent (Invitrogen) according to the manufacturer's protocol. Total RNA $(2 \mu \mathrm{g})$ was then subjected to PrimeScript ${ }^{\mathrm{TM}}$ reverse transcription (PrimeScript ${ }^{\mathrm{TM}} \mathrm{RT}$ reagent kit with gDNA Eraser), followed by RT-PCR (SYBR ${ }^{\circledR}$ Premix Ex Taq) (both from Takara) according to the manufacturer's instructions. The primers for RT-PCR were as follows: Bag-1 forward, 5'-GGTTCAGGCATTCCTAGCCGAGTG-3' and reverse, 5'-GTGGCGCCATTCTTCAGGGCA-3'; GAPDH sense, 5'-TGCACCACCAACTGCTTAGC-3' and antisense, 5'-GGC ATGGACTGTGGTCATGAG-3'. GAPDH was used as an internal control. The expression levels of the relative genes were calculated using control GAPDH mRNA and the $2^{-\Delta \Delta \mathrm{Ct}}$ method.

Western blotting. Total protein extracts were prepared using RIPA lysis buffer (Beyotime, Jiangsu, China) according to the manufacturer's instructions. The protein concentration of the lysates was evaluated using a BCA protein assay kit (Beyotime). Proteins (20 $\mu \mathrm{g})$ were separated by SDS-PAGE and were transferred onto poly(vinylidene difluoride) membranes (Millipore, Boston, MA, USA). The membrane was blocked for $120 \mathrm{~min}$ at room temperature with TBS 


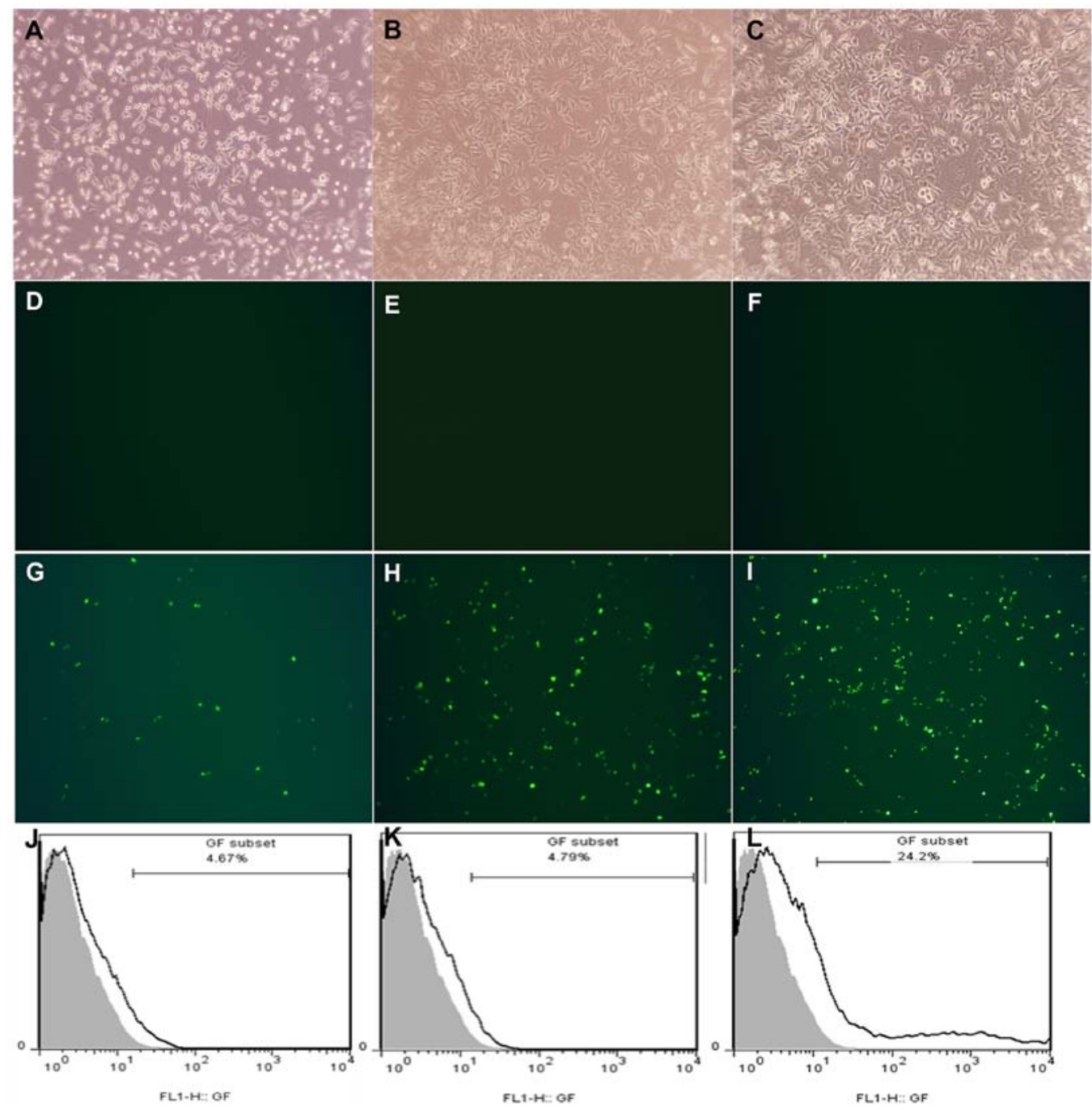

Figure 2. (A-C) Cultured LoVo cells, respectively at 24, 48 and 72 h. (D-F) Nano and plasmid transfections, and control groups LoVo cells observed under a fluorescent microscope after transfection for $72 \mathrm{~h}$. (G-I) Nano-plasmid transfection group of LoVo cells observed under a fluorescent microscope after transfection at 24, 48 and $72 \mathrm{~h}$. (J-L) Transfection efficiency results of Nano and Plasmid transfections, and Nano-Plasmid transfection groups after transfection for $72 \mathrm{~h}$ detected by flow cytometry.

blocking buffer. Blots were then probed with appropriate primary antibodies (anti-Bag-1, anti- $\beta$-catenin, anti-c-myc and anti- $\beta$-actin) (Proteintech, Wuhan, China) overnight at $4^{\circ} \mathrm{C}$. The membranes were washed with TBST, and were then incubated in horseradish peroxidase-conjugated secondary antibody (Thermo Fisher Scientific, Waltham, MA, USA) for $2 \mathrm{~h}$ at room temperature. After membranes were washed with TBST, the proteins were finally visualized by fluorography using an enhanced chemiluminescence system.

Statistical analysis. Results are expressed as mean \pm SD. All statistical analyses were carried out using SPSS 16.0. Differences between treatment conditions were assessed for statistical significance using one-way ANOVA, followed by the LSD or Dunnett's t-test method. $\mathrm{P}<0.05$ was considered to indicate a statistically significant result.

\section{Results}

Optimal ratio of nanoparticles and Bag-1 RNAi recombinant plasmid. Laser light scattering particle size analyzer showed that particle size of magnetic gold nanoparticles were $(99.65 \pm 2.83) \mathrm{nm}$, zeta potential was $(39.12 \pm 2.01) \mathrm{mV}$. Magnetic gold nanoparticles with positive charge surfaces can attract DNA to form a nanoparticle/plasmid complex. The magnetic gold nanoparticles mixed with plasmid according to mass ratio of 1: 1,2:1,3:1,4:1,5:1,10:1,15:1, respectively, underwent agarose gel electrophoresis (Fig. 1). It is clearly demonstrated that when the mass ratio reached 4, plasmid DNA starting to remain in wells due to DNA encapsulation and the compression by magnetic gold nanoparticles. The mass ratio of 4:1 was the optimal ratio to prepare the nanoparticle Bag-1 RNAi recombinant plasmid complex for further study.

Cell culture and transfection. After grouping and transfecting respectively, Nano and Plasmid transfections, and control group did not express green fluorescent protein (GFP) under a fluorescence microscope (Fig. 2D-F), while in Nano-Plasmid transfection group, the expression of GFP was observed in $24 \mathrm{~h}$ after transfection. Besides, the expression was increased in time and almost reach $72 \mathrm{~h}$ after transfection (Fig. 2G-I). Thus, we took $72 \mathrm{~h}$ transfection cells of each group to detect 


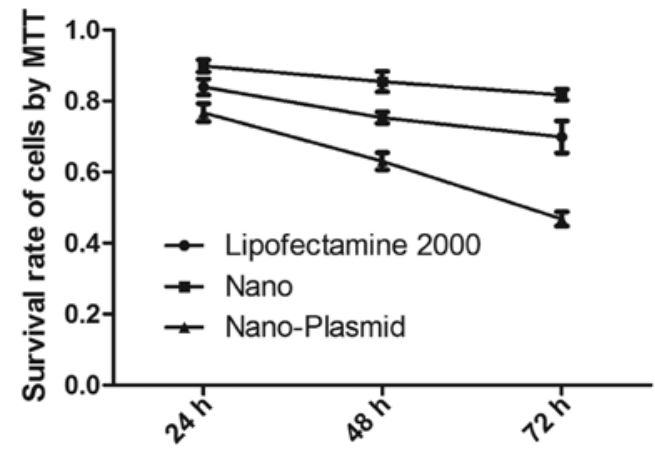

Figure 3. The survival rates, respectively, of Nano and Nano-Plasmid transfections, and Lipofectamine 2000 transfection groups, were evaluated by MTT assay.

the transfection efficiency by FCM, and considered the control group cells as zero for control, the transfection efficiency of Nano and Plasmid transfection groups were 4.67 and $4.79 \%$, respectively. Nano-Plasmid transfection group was $\sim 24.2 \%$ (Fig. 2J-L).

Cell viability assay. Comparing to the control group, MTT results showed that regardless of Nano and Nano-Plasmid transfections, or Lipofectamine 2000 transfection groups, LoVo cell viability tended to decrease as time prolonged. Cell viability of Nano-Plasmid transfection group was lower than the other groups at the same culture period $(\mathrm{P}<0.05)$. Cell activity of Nano transfection group was higher than Lipofectamine 2000 transfection reagent group $(\mathrm{P}<0.05)$ (Fig. 3). These results suggested that magnetic gold nanoparticles were less cytotoxic than Lipofectamine 2000 transfection reagent and cell viability of Nano-Plasmid transfection group was lower than Nano transfection group indicating exogenous gene was successfully transfected into cells, and showed increased cell apoptosis.

Cell apoptosis assay. The LoVo cells as control, cell apoptosis of Nano transfection, RNAi plasmid and Nano-Plasmid transfection group was $(17.95 \% \pm 0.024),(15.97 \% \pm 0.0046)$ and $(47.32 \% \pm 0.021)$, respectively. Apoptotic cells were mostly early apoptotic cells. The apoptosis rate of Nano-Plasmid transfection group was markedly increased compared to the other groups $(\mathrm{P}<0.05)$ (Fig. 4A and $\mathrm{B})$. Apoptotic/necrotic ratio of Nano transfection, Plasmid transfection and NanoPlasmid transfection groups was $(0.994 \pm 0.165),(2.075 \pm 0.172)$ and $(2.737 \pm 0.344)$, respectively. The difference between Nano-Plasmid transfection group compared to the others was statistically significantly different $(\mathrm{P}<0.05)$ (Fig. 4C).

RT-PCR. The results of Bag-1 mRNA expression detected by RT-PCR showed that CT value of Bag-1 in Nano-Plasmid transfection group was larger than the other three groups, and delayed plateau period. While CT value of Nano transfection, RNAi plasmid and control group was smaller and the plateau period started earlier. There were no significant differences among these groups. Comparing to control group, relative amounts of Bag-1 gene expression of Nano and Plasmid transfections, and Nano-Plasmid transfection groups were (1.126 \pm 0.334$),(1.212 \pm 0.503)$ and $(0.170 \pm 0.071)$, respectively. The expression of Nano-Plasmid transfection group was significantly lower than the others $(\mathrm{P}<0.05)$ (Fig. 5).
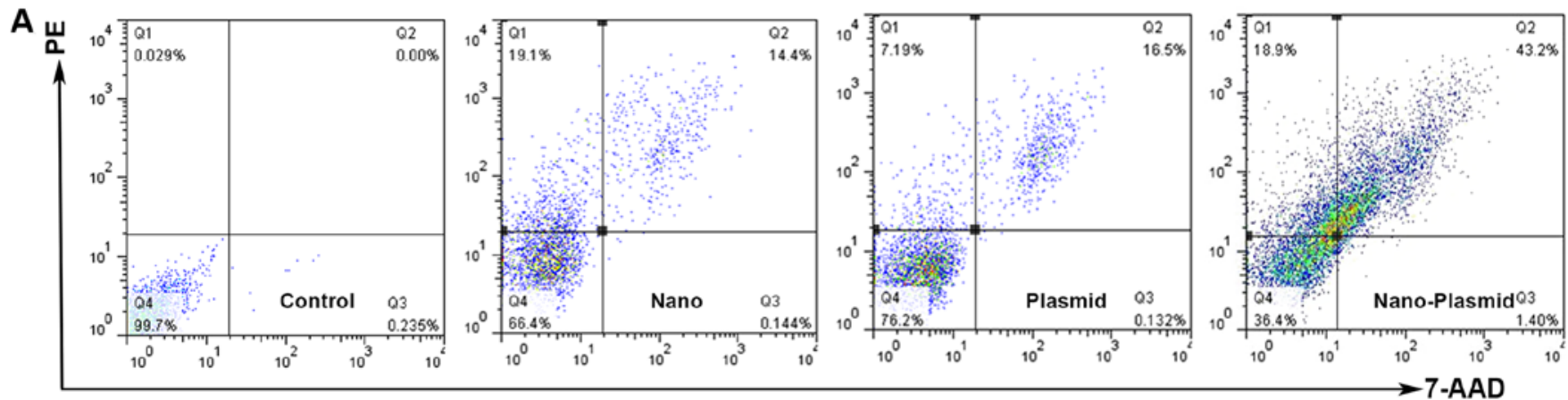

B

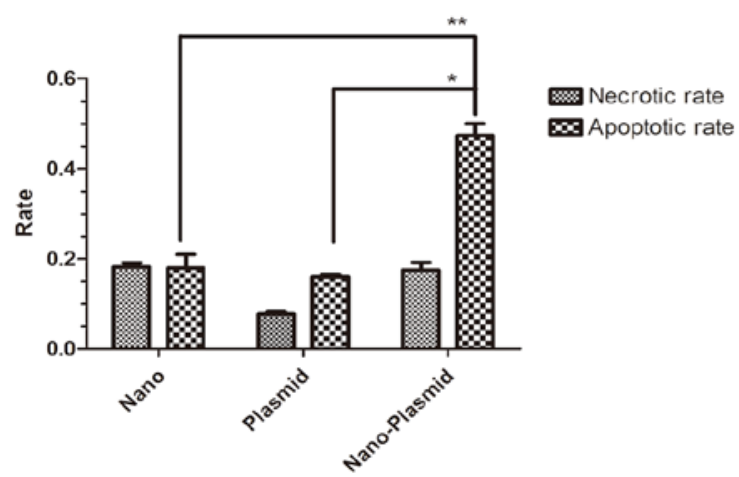

C

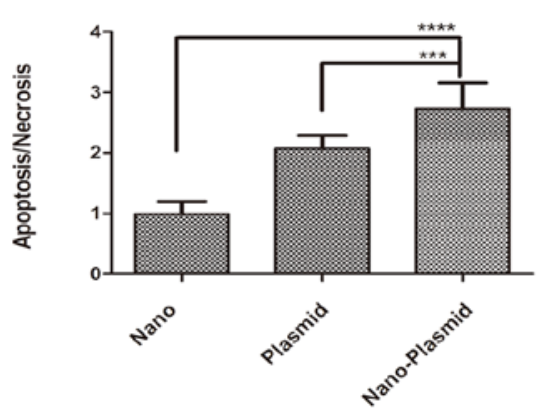

Figure 4. (A) Cell apoptosis of control, Nano and Plasmid transfections, and Nano-Plasmid transfection groups. (B) Necrotic and apoptotic rates of these groups. Differences between Nano-Plasmid transfection group and the other two groups were statistically significant $\left({ }^{*} \mathrm{P}<0.05\right.$, $\left.{ }^{* *} \mathrm{P}<0.05\right)$. $(\mathrm{C}) \mathrm{Apoptotic} / \mathrm{necrotic}$ ratio of Nano transfection, RNAi plasmid and Nano-Plasmid transfection groupsz. Differences between Nano-Plasmid transfection group and the other two groups were statistically significant $\left({ }^{* * *} \mathrm{P}<0.05,{ }^{* * * *} \mathrm{P}<0.05\right)$. 


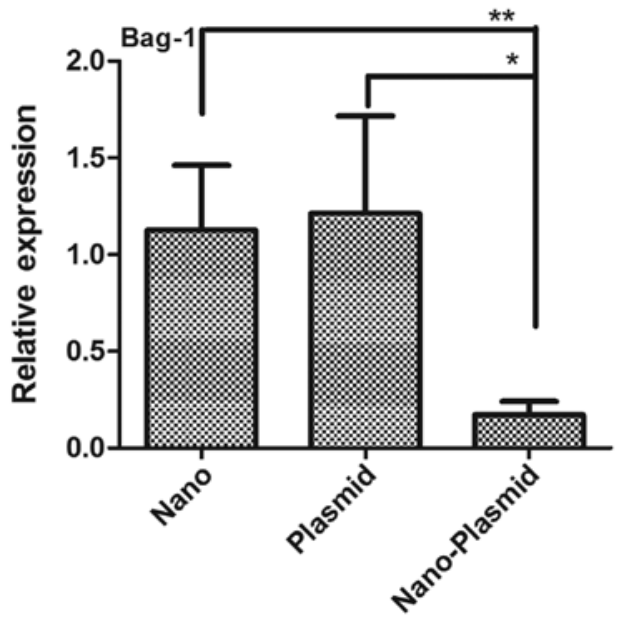

Figure 5. Demonstrates the relative amounts of Bag-1 gene expression of Nano and Plasmid transfections, and Nano-Plasmid transfection groups comparing to control group. Differences between Nano-Plasmid transfection group and the other two groups were statistically significant $\left({ }^{*} \mathrm{P}<0.05,{ }^{* *} \mathrm{P}<0.05\right)$.

Western blotting. Western blot results showed that the image intensity of bands of Nano-Plasmid transfection group were lower than bands of other groups (Fig. 6A). In the Nano-Plasmid transfection group, Bag-1 protein expression $(\mathrm{P}<0.05)$, c-myc protein expression $(\mathrm{P}<0.05)$, and $\beta$-catenin protein expression $(\mathrm{P}<0.05)$ decreased compared to the other three groups. Whereas, among Nano transfection, RNAi plasmid and control group, the differences of Bag-1, c-myc and $\beta$-actin protein expression showed no statistical significance (Fig. 6B).

\section{Discussion}

It is known that the initiation, development, invasion and metastasis of colon cancer are controlled by many different genes and various signal transduction pathways and involved in many important biological processes. Bag-1 which is only slightly expressed in normal tissues, is often expressed in breast, ovarian, oral cancer, intestinal and prostate cancer, glioma, and particularly in colon cancer (16-21). In the study of Li et al (22), patients with low expression in lung cancer had significantly longer survival period than patients with higher Bag-1 expression via RT-PCR detection which demonstrates that Bag-1 expression may be associated with poor prognosis. Bai et al (23) reported that Bag-1 can promote metastasis of colon cancer. Bag-1 is a positive regulator of Bcl-2 which is an anti-apoptotic gene. Bag-1 is not a Bcl-2 family member, but their promoter regions show high homology with Bcl-2 that makes it possible for them to form complex to promote anti-apoptotic function (5). Besides, Bag-1 can combine, for example, with estrogen, androgen and glucocorticoid receptor, realizing a variety of ways of inhibiting apoptosis (24-26). Combining with heat-shock cognate 70 (HSC70) and inducible heat-shock protein 70 (HSP70), Bag-1 can play a variety of physiological and pathological functions $(27,28)$. In the present study, recombinant RNAi plasmid was transfected into LoVo cells via the magnetic gold nanoparticle gene delivery system and expressed successfully in cells. In transfected LoVo cells, Bag-1 gene expression were significantly inhibited and apoptosis rate increased as the degree of Bag-1 gene suppression increased, which further confirms Bag-1 gene is an anti-apoptotic gene and has close relations with colon cancer development and prognosis.

Discoveries of oncogenes and tumor suppressor genes, and elucidation of mechanisms of cell signaling pathway, have greatly enriched knowledge of the mechanisms of carcinogenesis. Among these mechanisms, imbalance of $w n t / \beta$-catenin signaling pathway has been proven to have a significant correlation to a variety of tumors, including, cervical, breast, stomach and liver cancer, melanoma, and glioma, are found in $w n t / \beta$-catenin signaling pathway disorders (29-34). When wnt/ $\beta$-catenin signaling pathway abnormality occurs, intracellular $\beta$-catenin protein will accumulate, then free- $\beta$-catenin can enter the nucleus and activate expression of backward genes, leading to tumorigenesis $(35,36)$. In additional studies, we found that with Bag-1 gene expression suppressed expression of $\beta$-catenin protein and its downstream protein c-myc protein decrease, and

A
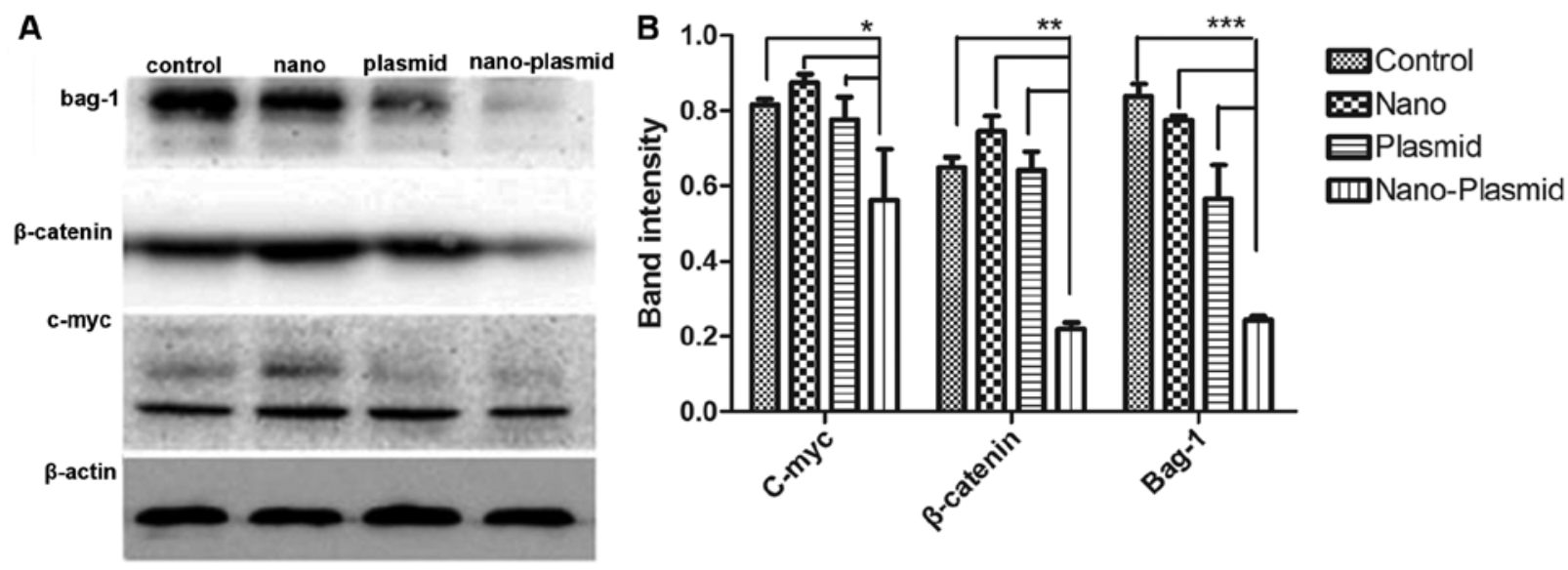

Figure 6. (A) The bands of Bag-1, c-myc, $\beta$-catenin and $\beta$-actin protein of Nano and Plasmid transfections, Nano-Plasmid transfection and control groups. (B) The band intensity rate of Bag-1, c-myc and $\beta$-catenin protein of Nano and Plasmid transfections, Nano-Plasmid transfection and control groups. Differences between Nano-Plasmid transfection group and the other three groups were statistically significant $\left({ }^{*} \mathrm{P}<0.05,{ }^{* *} \mathrm{P}<0.05,{ }^{* * * *} \mathrm{P}<0.05\right)$. 
speculate the mechanism of Bag-1 gene causing colon cancer may be related to the activation of $\beta$-catenin, that causing wnt $/ \beta$-catenin signaling pathway abnormality, then leading to overexpression of its downstream gene myc. Using small interfering RNA technology to silence Bag-1 gene, $\beta$-catenin activation can be reduced, therefore, making reduction of myc overexpression having a role in treating colon cancer. Besides, as known effective gene transfection and stable gene expression are the basis of successful gene therapy. The ideal gene delivery system should possess high gene delivery efficiency, low cytotoxicity, no physiological effects on normal cells as well as ease of use and reproducible properties (37-39). Nano-viral gene vectors have more advantages than viral gene vectors $(12,38)$. In the present study, we selected magnetic gold nanoparticles as gene vectors, which are relatively new in gene delivery systems. Magnetic nanoparticles can absorb nucleic acid to form nanoparticle nucleic acid complexes, in this way, DNA molecules can be protected from nuclease degradation. After coupling specific target molecules, targeted delivery is possible. Besides, DNA can achieve controlled release, and extend duration releasing time $(10,40,41)$. In this experiment, recombinant plasmids were successfully loaded, released and protected by magnetic gold nanoparticles. After successfully transfecting into LoVo cells, recombinant plasmids were expressed in cells with lower cytotoxicity. Magnetic gold nanoparticle gene vectors have huge potential as a gene delivery system, and mediating siRNA silencing Bag-1 is an effective gene therapy method for colon cancer.

\section{References}

1. Siegel R, Ma J, Zou Z and Jemal A: Cancer statistics, 2014. CA Cancer J Clin 64: 9-29, 2014.

2. Qiu K, Yu B, Huang H, Zhang P, Huang J, Zou S, Chen Y, Ji L and Chao $\mathrm{H}$ : A dendritic nano-sized hexanuclear ruthenium(II) complex as a one- and two-photon luminescent tracking non-viral gene vector. Sci Rep 5: 10707, 2015.

3. Şalva E, Turan SO, Ekentok C and Akbuğa J: Generation of stable cell line by using chitosan as gene delivery system. Cytotechnology: Jul 2, 2015 (Epub ahead of print).

4. Hassan M, Watari H, AbuAlmaaty A, Ohba Y and Sakuragi N: Apoptosis and molecular targeting therapy in cancer. Biomed Res Int 2014: 150845, 2014

5. van der Zee JA, Ten Hagen TL, Hop WC, van Dekken H, Dicheva BM, Seynhaeve AL, Koning GA, Eggermont AM and van Eijck CH: Bcl-2 associated anthanogen-1 (Bag-1) expression and prognostic value in pancreatic head and periampullary cancer. Eur J Cancer 49: 323-328, 2013.

6. Sun N, Meng Q and Tian A: Expressions of the anti-apoptotic genes Bag-1 and Bcl-2 in colon cancer and their relationship. Am J Surg 200: 341-345, 2010.

7. Clemo NK, Collard TJ, Southern SL, Edwards KD, Moorghen M, Packham G, Hague A, Paraskeva C and Williams AC: BAG-1 is up-regulated in colorectal tumour progression and promotes colorectal tumour cell survival through increased NF-kappaB activity. Carcinogenesis 29: 849-857, 2008

8. Kievit FM and Zhang M: Surface engineering of iron oxide nanoparticles for targeted cancer therapy. Acc Chem Res 44: 853-862, 2011.

9. Liu M, Wang Z, Zong S, Chen H, Zhu D, Zhong Y and Cui Y: Remote-controlled DNA release from $\mathrm{Fe}_{3} \mathrm{O}_{4} @ A u$ nanoparticles using an alternating electromagnetic field. J Biomed Nanotechnol 11: 979-987, 2015

10. Raji MA, Amara M, Amoabediny G, Tajik P, Barin A, Magierowski S and Ghafar-Zadeh E: Cytotoxicity of synthesized iron oxide nanoparticles: Toward novel biomarkers of colon cancer. Conf Proc IEEE Eng Med Biol Soc 2014: 6179-6182, 2014.
11. Wan Q, Xie L, Gao L, Wang Z, Nan X, Lei H, Long X, Chen ZY, He CY, Liu G, et al: Self-assembled magnetic theranostic nanoparticles for highly sensitive MRI of minicircle DNA delivery. Nanoscale 5: 744-752, 2013.

12. Sun NF, Liu ZA, Huang WB, Tian AL and Hu SY: The research of nanoparticles as gene vector for tumor gene therapy. Crit Rev Oncol Hematol 89: 352-357, 2014.

13. Singh D, McMillan JM, Kabanov AV, Sokolsky-Papkov M and Gendelman HE: Bench-to-bedside translation of magnetic nanoparticles. Nanomedicine 9: 501-516, 2014.

14. Ben Q, An W, Fei J, Xu M, Li G, Li Z and Yuan Y: Downregulation of L1CAM inhibits proliferation, invasion and arrests cell cycle progression in pancreatic cancer cells in vitro. Exp Ther Med 7: 785-790, 2014.

15. Zhou Y, Xiong M, Niu J, Sun Q, Su W, Zen K, Dai C and Yang J: Secreted fibroblast-derived miR-34a induces tubular cell apoptosis in fibrotic kidney. J Cell Sci 127: 4494-4506, 2014.

16. Maddalo D, Neeb A, Jehle K, Schmitz K, Muhle-Goll C, Shatkina L, Walther TV, Bruchmann A, Gopal SM, Wenzel W, et al: A peptidic unconjugated GRP78/BiP ligand modulates the unfolded protein response and induces prostate cancer cell death PLoS One 7: e45690, 2012.

17. Roth W, Grimmel C, Rieger L, Strik H, Takayama S, Krajewski S, Meyermann R, Dichgans J, Reed JC and Weller M: Bag-1 and $\mathrm{Bcl}$-2 gene transfer in malignant glioma: Modulation of cell cycle regulation and apoptosis. Brain Pathol 10: 223-234, 2000.

18. Wood J, Lee SS and Hague A: Bag-1 proteins in oral squamous cell carcinoma. Oral Oncol 45: 94-102, 2009.

19. Aust S, Pils S, Polterauer S, Horvat R, Cacsire Castillo-Tong D, Pils D, Dudek G, Schmid B, Speiser P, Reinthaller A, et al: Expression of Bcl-2 and the antiapoptotic BAG family proteins in ovarian cancer. Appl Immunohistochem Mol Morphol 21: 518-524, 2013.

20. Liu H, Lu S, Gu L, Gao Y, Wang T, Zhao J, Rao J, Chen J, Hao X and Tang SC: Modulation of BAG-1 expression alters the sensitivity of breast cancer cells to tamoxifen. Cell Physiol Biochem 33: 365-374, 2014.

21. Mashukova A, Kozhekbaeva Z, Forteza R, Dulam V, Figueroa Y, Warren R and Salas PJ: The BAG-1 isoform BAG-1M regulates keratin-associated Hsp70 chaperoning of aPKC in intestinal cells during activation of inflammatory signaling. J Cell Sci 127: 3568-3577, 2014

22. Li P, Wang YD, Cheng J, Chen JC and Ha MW: Association between polymorphisms of BAG-1 and XPD and chemotherapy sensitivity in advanced non-small-cell lung cancer patients treated with vinorelbine combined cisplatin regimen. Tumour Biol: Jun 30, 2015 (Epub ahead of print).

23. Bai YX, Yi JL, Li JF and Sui H: Clinicopathologic significance of BAG1 and TIMP3 expression in colon carcinoma. World J Gastroenterol 13: 3883-3885, 2007.

24. Knee DA, Froesch BA, Nuber U, Takayama S and Reed JC: Structure-function analysis of Bag1 proteins. Effects on androgen receptor transcriptional activity. J Biol Chem 276: 12718-12724, 2001.

25. Schmidt U, Holsboer F and Rein T: Role of the hsp70 cochaperone BAG1 in glucocorticoid receptor function and stress-related diseases. Proc Natl Acad Sci USA 105: E101; author reply E102, 2008.

26. Brendel A, Felzen V, Morawe T, Manthey D and Behl C: Differential regulation of apoptosis-associated genes by estrogen receptor alpha in human neuroblastoma cells. Restor Neurol Neurosci 31: 199-211, 2013.

27. Brive L, Takayama S, Briknarová K, Homma S, Ishida SK, Reed JC and Ely KR: The carboxyl-terminal lobe of Hsc70 ATPase domain is sufficient for binding to BAG1. Biochem Biophys Res Commun 289: 1099-1105, 2001.

28. Rauch JN and Gestwicki JE: Binding of human nucleotide exchange factors to heat shock protein 70 (Hsp70) generates functionally distinct complexes in vitro. J Biol Chem 289: 1402-1414, 2014.

29. Jang GB, Kim JY, Cho SD, Park KS, Jung JY, Lee HY, Hong IS and Nam JS: Blockade of Wnt/ $\beta$-catenin signaling suppresses breast cancer metastasis by inhibiting CSC-like phenotype. Sci Rep 5: 12465, 2015.

30. Li F, Wang T and Tang S: SOX14 promotes proliferation and invasion of cervical cancer cells through $\mathrm{Wnt} / \beta$-catenin pathway. Int J Clin Exp Pathol 8: 1698-1704, 2015. 
31. Akaboshi S, Watanabe S, Hino Y, Sekita Y, Xi Y, Araki K, Yamamura K, Oshima M, Ito T, Baba H, et al: HMGA1 is induced by Wnt/beta-catenin pathway and maintains cell proliferation in gastric cancer. Am J Pathol 175: 1675-1685, 2009.

32. Wang Y, He L, Du Y, Zhu P, Huang G, Luo J, Yan X, Ye B, Li C, $\mathrm{Xia} \mathrm{P}$, et al: The long noncoding RNA lncTCF7 promotes selfrenewal of human liver cancer stem cells through activation of Wnt signaling. Cell Stem Cell 16: 413-425, 2015.

33. Atkinson JM, Rank KB, Zeng Y, Capen A, Yadav V, Manro JR, Engler TA and Chedid M: Activating the Wnt/ $\beta$-Catenin pathway for the treatment of melanoma - Application of LY2090314, a novel selective inhibitor of glycogen synthase kinase-3. PLoS One 10: e0125028, 2015.

34. Hu T, Xie N, Qin C, Wang J and You Y: Glucose-regulated protein 94 is a novel glioma biomarker and promotes the aggressiveness of glioma via Wnt/ $\beta$-catenin signaling pathway. Tumour Biol: Jun 25, 2015 (Epub ahead of print).

35. Cai J, Maitra A, Anders RA, Taketo MM and Pan D: $\beta$-Catenin destruction complex-independent regulation of Hippo-YAP signaling by APC in intestinal tumorigenesis. Genes Dev 29: 1493-1506, 2015.
36. Mir R, Pradhan SJ, Patil P, Mulherkar R and Galande S: Wnt/ßcatenin signaling regulated SATB1 promotes colorectal cancer tumorigenesis and progression. Oncogene: Jul 13, 2015 (Epub ahead of print). doi: 10.1038/onc.2015.232.

37. Zhao R, Peng X, Chu H and Song W: Phosphorylatable short peptide conjugated chitosan mediated gene therapy for repair of articular cartilage defect in rabbits. Zhongguo Xiu Fu Chong Jian Wai Ke Za Zhi 28: 1346-1352, 2014 (In Chinese).

38. Son S, Namgung R, Kim J, Singha K and Kim WJ: Bioreducible polymers for gene silencing and delivery. Acc Chem Res 45: 1100-1112, 2012

39. Whitehouse A: Herpesvirus saimiri: A potential gene delivery vector (Review). Int J Mol Med 11: 139-148, 2003.

40. Vijayanathan V, Thomas T and Thomas TJ: DNA nanoparticles and development of DNA delivery vehicles for gene therapy. Biochemistry 41: 14085-14094, 2002.

41. Jingting $C$, Huining Land YiZ:Preparationand characterization of magnetic nanoparticles containing $\mathrm{Fe}_{3} \mathrm{O}_{4}$-dextran-anti- $\beta$-human chorionic gonadotropin, a new generation choriocarcinomaspecific gene vector. Int J Nanomed 6: 285-294, 2011. 